\title{
RESISTÊNCIA SIMPLES À COMPRESSÃO E MÓDULO DE ELASTICIDADE DO CONCRETO PRODUZIDO COM SUBSTITUIÇÃO PARCIAL DE AGREGADO MIÚDO POR RESÍDUOS PLÁSTICOS
}

\section{SIMPLECOMPRESSIVESTRENGHT AND ELASTICITYMODULUS OFCONCRETEPRODUCED WITH PARCIAL SUBSTITUTION OF THE FINE AGGREGATE BY PLASTIC WASTE}

\author{
Carlos Humberto Martins, Dr. (UEM); \\ Giordanno Pietro Altoé Marcantonio (UEM); \\ Aguinaldo Lenine (UEM)

\section{Palavras Chave} \\ Concreto; Resíduos Plásticos; Sustentabilidade
}

\section{Key Words}

Concrete; Plastic Waste; Sustentability

\section{RESUMO}

Este trabalho tem por objetivo viabilizar meios de utilização e destinação de resíduos de garrafa PET - moídas e trituradas, Pellets de sacolas plásticas e o resíduo industrial Cyrel ${ }^{\circledR}$ moído e triturado. Para isso, realizou-se, primeiramente, uma pesquisa bibliográfica e ensaios de caracterização dos resíduos - granulometria e massa específica. Posteriormente, produziu-se traços de concreto utilizando substituição de agregados miúdos pelos resíduos anteriormente citados de forma individual, na ordem de $10 \%$ em massa e, após isso, foram realizados ensaios de Módulo de Elasticidade Não Destrutivo e Resistência Simples à Compressão aos 28 dias. Pode-se concluir que a substituição parcial de agregado miúdo pelos resíduos plásticos estudados é viável; propondo-se, dessa forma, uma alternativa sustentável de destinação para esses materiais.

\section{ABSTRACT}

This work has as an objective to make feasible ways of reuse and proper destination to the PET bottle waste - ground and crushed, plastic bag pellets and ground and crushed Cyrel ${ }^{\circledR}$. For such purpose, a bibliographical research and characterization tests of the residues - granulometry and specific mass - were made. Subsequently, traces of concrete were produced using partial substitution of small aggregates for the aforementioned residues individually, in the order of $10 \%$ by mass, and after that, a Non-Destructive Elasticity Modulus test and Simple Compressive Strength test were performed at 28 days. It can be concluded that the partial replacement of small aggregates by the plastic waste studied is viable; thus proposing an sustainable alternative destination for these materials. 


\section{INTRODUÇÃO}

A construção civil é uma atividade indispensável para o desenvolvimento de um país; entretanto, há uma grande demanda de matéria prima para que ela ocorra. Atualmente, no Brasil, um dos materiais mais utilizados é o concreto; entretanto, sua produção não é um processo limpo e sustentável do ponto de vista ambiental, devido à grande emissão de gás carbônico no processo de sintetização do clínquer (GONÇALVES, 2017).

Paralelamente, a produção exacerbada de resíduos plásticos é também responsável pela assolação do meio ambiente, sendo que a geração desses resíduos tem aumentado exponencialmente nos últimos anos, segundo o Ministério do Meio Ambiente (BRASIL, 2011). Portanto, a fim de minorar os danos ambientais, a maioria dos resíduos produzidos pode ser reciclada, de modo a serem reutilizados e incorporados na produção de novos produtos.

Destarte, o presente trabalho tem por objetivo propor e avaliar traços de concreto com substituição parcial do agregado miúdo por resíduos plásticos. Uma vez que grandes quantidades dos resíduos em questão são produzidos e prejudicam ao meio ambiente por não terem um destino adequado, busca-se, com este estudo, fornecer uma possibilidade de reutilização deles, sendo favorável à preservação do meio ambiente.

\section{REVISÃO TEÓRICA}

\subsection{Concreto}

A produção de cimento é, atualmente, uma das maiores fontes responsáveis pela emissão de gás carbônico, sendo considerada um processo não sustentável do ponto de vista ambiental. Aliado a isso, na construção civil, um dos materiais mais utilizados devido à grande facilidade de manuseabilidade e moldabilidade é o concreto, cuja composição é a mistura de cimento, agregado miúdo (areia), agregado graúdo (brita) e água (GONÇALVES, 2017).

Segundolevantamento realizado peloDepartamento da Indústria da Construção (Deconcic) da Federação das Indústrias do Estado de São Paulo (Fiesp) (FADUL, 2015), o setor da construção civil representou, em 2015, 10,1\% do PIB total brasileiro e, além disso, Mehta e Monteiro (2008) colocam que o processo produtivo de uma tonelada de clínquer emite aproximadamente uma tonelada de gás carbônico (CO2) na atmosfera, bem como à luz dos dados publicados pela Câmara Brasileira da Indústria da Construção (CBIC), o consumo nacional de cimento foi de 71.703.179 toneladas em 2014 e 65.315.622 toneladas em 2015. Desse modo, somente a produção de cimento no mundo anualmente é responsável por aproximadamente $7,0 \%$ das emissões globais de $\mathrm{CO} 2$ ( 1,5 bilhões de toneladas).

Diante do exposto, percebe-se a necessidade, tanto econômica como ambiental, de se oferecerem alternativas de materiais que diminuam o consumo de cimento. Dessa forma, considerou-se a utilização de materiais plásticos que substituam parcialmente algum dos componentes do concreto - no caso, do agregado miúdo.

\subsection{Resíduos Plásticos}

Atualmente, o consumo de plástico no mundo é grande em diversos itens, como por exemplo em sacolas plásticas. De acordo com o Ministério do Meio Ambiente (BRASIL, 2011), anualmente, são distribuídas de 500 biIhões a 1 trilhão de sacolas plásticas em todo o mundo.

Utilizando, dessa forma, os plásticos na composição do concreto, esses resíduos deixariam de serem rejeitos e tornar-se-iam matéria prima, gerando um processo sustentável.

O plástico, segundo Piatti e Rodrigues (2005), é uma substância oriunda do Petróleo, pertencente ao grupo dos polímeros, formado por uma mistura de compostos orgânicos, na qual os hidrocarbonetos (substâncias ricas em carbono e hidrogênio) aparecem em maior quantidade.

Santos (2005) cita que é possível dividir os polímeros, segundo características tecnológicas, em dois grupos: os Termoplásticos (também chamados flexíveis) e os Termorrígidos (também conhecidos por rígidos).

Os polímeros termoplásticos têm interações menos fortes - do tipo Van der Waals, de forma que a quebra dessas ligações não causa a degradação do material, possibilitando a sua reciclagem pelo processo de fusão e remodelagem. Já os materiais termorrígidos são compostos por ligações mais fortes - do tipo cruzadas; sendo que, quando quebradas, geralmente ocorre a degradação do polímero. Dessa forma, o processo de reciclagem de um polímero termorrígido é inviável (SANTOS, 2005).

Por último, encontram-se os plásticos, que podem ser classificados em rígidos e flexíveis. Estes foram apresentados no início deste sub tópico, sendo os plásticos rígidos também chamados de termorrígidos, e os flexíveis, termoplásticos.

Dentre os termoplásticos conhecidos, conforme citam Romão, Spinacé e Paoli (2009), estão os polietilenos de baixa densidade (sacolas plásticas de mercado), o Poli (Tereftaleno de Etileno) também conhecido como PET, e o Cyrel ${ }^{\oplus}$. 


\subsection{1 $\mathrm{Cyrel}^{\oplus}$}

Primeiramente, para compreender a origem deste material, é necessário compreender o processo em que ele é utilizado, cujo nome é Flexografia. A flexografia pode ser descrita, segundo a ABTG (2002) como um sistema de impressão gráfica, na qual existe uma forma relevográfica em que se aplica a tinta e, posteriormente, gravam-se suas informações local desejado. Esse sistema é amplamente utilizado na indústria alimentícia, servindo também para impressões em etiquetas, embalagens, copos descartáveis e toalhas de papel, por exemplo.

O Cyrel ${ }^{\oplus}$ é um fotopolímero desenvolvido pela empresa multinacional Dupont, com a finalidade de ser utilizado especificamente no processo flexográfico, como matéria prima para o clichê - forma relevográfica. Segundo Dupont (2017), o trabalho com o Cyrel $^{\circledR}$ na indústria flexográfica permite uma melhoria em controle do processo, qualidade e no produto final, além de reduzir em até $75 \%$ o tempo de produção de uma chapa. A utilização do material gera uma redução de consumo de $15 \%$, e gera menos emissões de gases causadores do efeito estufa. A figura 1 a seguir representa uma chapa flexográfica de Cyrel ${ }^{\oplus}$.

Figura 01 - Chapa flexográfica de Cyrel ${ }^{\circledast}$

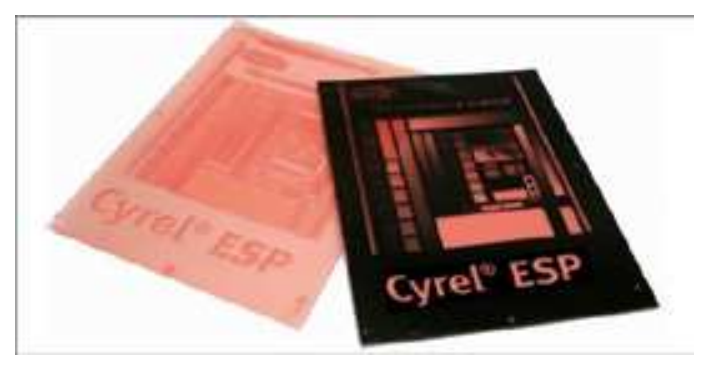

Fonte: Dupont (2017)

Atualmente, o material mais utilizado para composição dos clichês é o Cyrel ${ }^{\oplus}$. De acordo com Flexo Tech (2014), mais de 180 mil toneladas de resíduos de chapas flexográficas são depositadas no Reino Unido a cada ano e, uma vez que a chapa de impressão foi moldada, sua utilização e vida útil são limitadas às informações nela contidas; resultando, por fim, em seu descarte. Sendo assim, aliado ao fato de que o $\mathrm{Cyrel}^{\oplus}$ é um material de decomposição muito lenta, é interessante a busca de um destino sustentável para esse resíduo.

\subsubsection{Resíduos Plásticos de Sacolas - Pellets}

Um dos grandes problemas ambientais da atualidade é o uso excessivo e descarte impróprio de sacolas plásticas no meio ambiente. Como exemplo, Guimarães e Albuquerque (2010) citam que as maiores vítimas nos oceanos do descarte inadequado de sacolas plásticas são baleias, golfinhos, focas, tartarugas e aves marinhas, que confundem as sacolas com alimento, e acabam morrendo sufocadas por obstrução do aparelho digestivo. Esses autores ainda incluem que, anualmente, mais de 100 mil animais morrem devido à intoxicação por ingestão de plástico. Além disso, esses materiais dificultam a biodegradação de matéria orgânica, por serem impermeáveis; criando, dessa forma, acúmulos de gás metano nos bolsões, liberando todo o gás metano para a atmosfera quando se remove o lixo.

Ziegler (2010) afirma que o material em questão leva um grande período de tempo para se deteriorar. Segundo a autora, o plástico componente das sacolas leva em torno de 200 anos para se decompor, caso esteja soterrado no lixo. Se as sacolas estiverem expostas à radiação solar, esse período cai para um ano. Porém, seu elevado tempo de decomposição é secundário se comparado com a problemática de que, uma vez que as sacolas são compostas de poliuretano (advindo do petróleo e do etileno), a produção desses recipientes também é altamente nociva ao meio ambiente, acentuando o efeito estufa.

Por esses motivos, é vantajoso buscar um destino para as sacolas plásticas. Para que possa ser utilizado como matéria prima, esse material é moído, triturado e, após isso, comprimido em formato de grãos, recebendo o nome de Pellets, como ilustrado na figura 2 a seguir.

Figura 02 - Pellets de sacolas plásticas

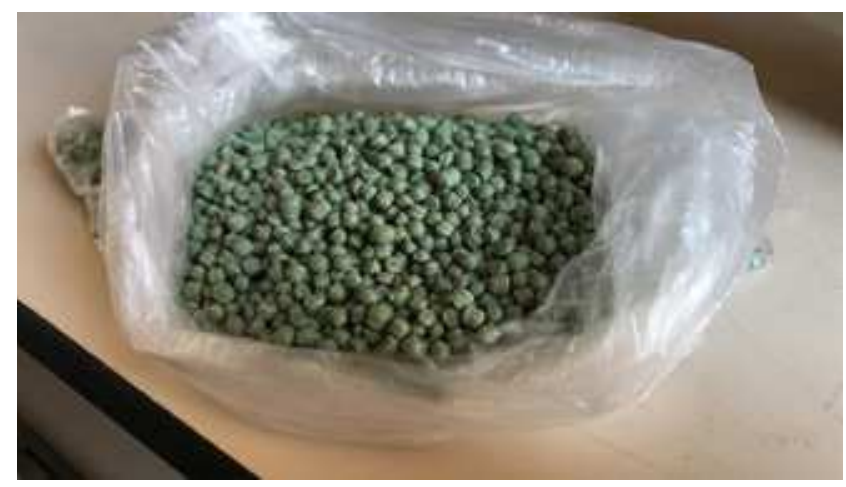

Fonte: Elaborado pelos autores

\subsubsection{PET}

O PET, cujo nome científico é poli(teraftalato de etileno), ou também poli(etileno tereftalato), foi descoberto por Whinfield e Dickson, no ano de 1941 (FORMIGONI; CAMPOS, 2006). Incialmente, concorrendo no mercado diretamente contra as garrafas de vidro, as vantagens apresentadas por este material superaram em muito o 
material tradicional. Pereira, Machado e Silva (2001) citam o PET como agente facilitador do transporte, reduzindo os custos consideravelmente a ponto de se tornar viável o descarte da embalagem. A garrafa de PET ainda apresenta meIhor desempenho que a de vidro em alguns aspectos, apresentando maior eficiência em preservar o gás das bebidas.

Leite (2003 apud FORMIGONI; CAMPOS, 2006) aponta que um dos grandes problemas é a quantidade excessiva de resíduos gerados. A dificuldade é referente ao volume elevado que os plásticos ocupam no descarte em aterros sanitários: embora a massa deles seja de aproximadamente $10,0 \%$, o volume ocupado chega ao dobro do valor. Inclusive, os plásticos levam um longo período de tempo para se decomporem. Dentre outros fatores, isso resulta no encarecimento da coleta, transporte e descarte final deste tipo de resíduo, surgindo, assim, descartes inapropriados e contaminação do meio ambiente.

Deste modo, busca-se cada vez mais reutilizar esses resíduos de forma sustentável, de modo a solucionar um dos grandes problemas relacionados ao meio ambiente dos dias de hoje. Segundo dados da Abipet (2013), historicamente, $90 \%$ do consumo de PET no Brasil é usado para produção de embalagens de bebidas e alimentos (refrigerantes, água, óleo comestivel, etc.). Em 2011, esse valor atingiu 515.000 toneladas.

\section{MATERIAIS E MÉTODOS}

Para a realização dos ensaios, os materiais utilizados foram:

- Cimento: o cimento utilizado foi o CP II - F - 32 da marca 'Supremo', escolhido devido ao fato de o mesmo não possuir escória ou pozolana em sua composição (GONÇALVES, 2017);

- Agregado Miúdo: o agregado miúdo utilizado foi a areia média quartzoza, obtida no Depósito Santa Terezinha, em Maringá, $\mathrm{PR}$;

- Agregado Graúdo: o agregado graúdo utilizado foi a brita 01, obtida no Depósito Alvorada, em Maringá, PR;

- Água: A água utilizada é a água potável fornecida pela SANEPAR (Companhia de Abastecimento de Água do Paraná), a partir do sistema de abastecimento de água da cidade de Maringá-PR.

- Resíduos plásticos;

Primeiramente foram realizados ensaios de caracterização dos agregados graúdo e miúdo, bem como a caracterização dos resíduos plásticos. Cita-se que foram realizados ensaios de granulometria com os três resíduos e com os agregados miúdo e graúdo segundo instruções da norma NBR 7217/ 1987 (ABNT, 1987).
A seguir, na Tabela 1, são apresentadas as normas utilizadas para o ensaio de massa específica dos resíduos plásticos e os respectivos resultados.

Tabela 01: Massa específica e norma utilizada para resíduos plásticos

\begin{tabular}{|l|l|l|}
\hline \multirow{2}{*}{ Material } & \multirow{2}{*}{ Norma utilizada } & $\begin{array}{l}\text { Massa Específica } \\
\left(\mathbf{g} / \mathbf{c m}^{\mathbf{3}}\right)\end{array}$ \\
\hline Cyrel $^{\circledR}$ & \multirow{3}{*}{ NM 23/ 2000} & 1,09 \\
\cline { 1 - 1 } & & 1,38 \\
PET & & 0,88 \\
\hline
\end{tabular}

Fonte: elaborado pelos autores

O traço utilizado como referência foi o traço desenvolvido por Nunes (2009), apresentando um consumo de cimento de $367,6 \mathrm{Kg} / \mathrm{m}^{3}$. As porcentagens de substituição de cada traço encontram-se na tabela 2 a seguir.

Tabela 02: Traços unitários

\begin{tabular}{c|c|c|c|c|c|c}
\hline Traço & Descrição & C & A & B1 & a/c & Residuos \\
\hline 01 & Referencia & 1,0 & 2,06 & 2,94 & 0,56 & - \\
\hline 02 & $10 \%$ Cyrel (6) & 1,0 & 1,85 & 2,94 & 0,56 & 0,21 \\
\hline 03 & $10 \%$ PET & 1,0 & 1,85 & 2,94 & 0,56 & 0,21 \\
\hline 04 & $10 \%$ Pellets & 1,0 & 1,85 & 2,94 & 0,56 & 0,21
\end{tabular}

Fonte: Elaborado pelos autores

Devido à grande diferença entre a massa específica dos resíduos e a massa específica do agregado miúdo, fo realizada a compensação do volume do material substituído. Caso a compensação não fosse realizada, haveria um volume maior de cada resíduo plástico em seus respectivos traços, necessitando assim de uma quantidade maior de água para envolver todas as partículas. $O$ método adotado também foi utilizado por outros pesquisadores (GONÇALVES, 2017; LEITE, 2001; MORETTI, 2014), e se baseia na "equação (1)" para realizar a compensação:

(1) $\quad$ Residuos $=$ MAreia $\times \frac{\text { Ykariduo }}{\gamma \text { Arria }}$

Deste modo, a Tabela 3 apresenta os traços unitários em massa. 
Tabela 03: Traços unitários em massa

\begin{tabular}{|c|c|c|c|c|c|c|}
\hline Trace & $\begin{array}{c}\text { Cimento } \\
{[\mathrm{kg}]}\end{array}$ & $\begin{array}{c}\text { Areia } \\
{[\mathrm{kg}]}\end{array}$ & $\begin{array}{c}\text { Brita } \\
\mathbf{0 1}[\mathrm{kg}]\end{array}$ & $\begin{array}{c}\text { Igua } \\
{[\mathbf{L}]}\end{array}$ & $\begin{array}{c}\text { Residuo } \\
{[\mathrm{kg}]}\end{array}$ & $\begin{array}{c}\text { Residuo } \\
\text { corrigido } \\
{[\mathrm{kg}]}\end{array}$ \\
\hline Referencua & 12,703 & 26,169 & 37,348 & 7,050 & - & - \\
\hline $\begin{array}{c}10 \% \text { Cyre] } \\
\varnothing\end{array}$ & 12,357 & 22,910 & 37,348 & 7,050 & 2,546 & 1,039 \\
\hline $10 \%$ PET & 12,357 & 22,910 & 37,348 & 7,050 & 2,546 & 1,324 \\
\hline $\begin{array}{c}10 \% \% \\
\text { Pellets }\end{array}$ & 12,357 & 22,910 & 37,348 & 7,050 & 2,546 & 0,838 \\
\hline
\end{tabular}

Fonte: Elaborado pelos autores

A figura 3 apresentada a seguir mostra a moldagem dos corpos de prova à direita, bem como sua cura em câmara úmida à esquerda. Para cada traço foram moldados 20 corpos de prova.

Figura 03: Corpos de prova moldados e em processo de cura em câmara úmida

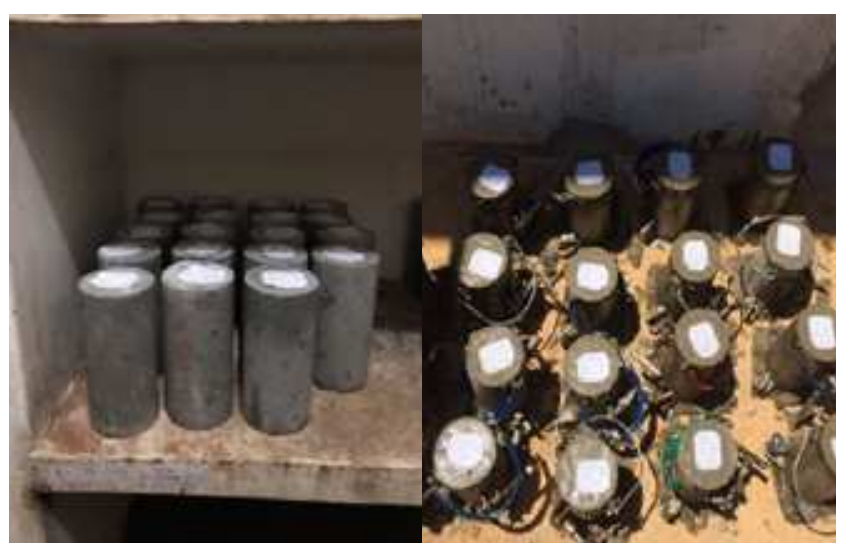

Fonte: Elaborado pelos autores

Foram adotados parâmetros de dosagem para os traços conforme o descrito por Gonçalves (2017), sendo eles:

- Relação água/cimento, calculada em massa, menor que 0,60, conforme prescrito pela NBR 6118 (ABNT, 2014) para casos de concreto armado com classe de agressividade II;

- Resistência à compressão acima de 25,0 MPa devido à exposição do concreto à uma classe de agressividade II, exposto pela NBR 6118 (ABNT, 2014);

- Abatimento do tronco de cone de $70 \pm 10 \mathrm{~mm}$, buscando assim um concreto plástico, sem utilização de aditivos, como detalhado por Leite (2001) e Moretti (2014);

- Condições de preparo: materiais são medidos em massa, conforme a NBR 12.655 (ABNT, 2015).

A tabela 4 apresenta a quantidade de corpos de prova de cada traço destinados para os ensaios. Cita-se que os ensaios de resistência simples à compressão e módulo de elasticidade não destrutivo foram realizados com 28 dias.
Tabela 04: Corpos de prova e ensaios

\begin{tabular}{|c|c|c|c|c|}
\hline Traço & $\begin{array}{c}N^{0} \text { Total } \\
\text { de } \\
\text { corpos } \\
\text { de prova }\end{array}$ & $\begin{array}{c}\text { Resistência } \\
\text { Simples } \\
\text { a } \\
\text { Compressão }\end{array}$ & $\begin{array}{c}\text { Módulo de } \\
\text { elasticidade } \\
\text { não } \\
\text { destrutivo }\end{array}$ & Absorção \\
\hline Referência & 19 & 13 & 03 & 03 \\
\hline $\begin{array}{c}10 \% \text { Cyrel } \\
8\end{array}$ & 19 & 13 & 03 & 03 \\
\hline $10 \%$ PET & 21 & 15 & 03 & 03 \\
\hline $10 \%$ Pellets & 19 & 13 & 03 & 03 \\
\hline
\end{tabular}

Fonte: Elaborado pelos autores

No que tange o ensaio de resistência simples à compressão, cita-se que para garantir a uniformidade de tensões na superfície do corpo de prova, todos os copos de prova passaram por um processo de retifica, com o intuito de regularizar a superfície e remover qualquer irregularidade.

Referente ao ensaio de módulo de elasticidade não destrutivo, o mesmo foi obtido com o auxílio de um equipamento de nome Sonelastic ${ }^{\oplus}$. O princípio do método é o da excitação por impulso, na qual o corpo de prova é golpeado e emite um som único e característico, que depende das propriedades elásticas, da dimensão e massa do material. $O$ método traz inúmeras vantagens, como a metodologia não destrutiva, a rapidez e precisão na prática e a facilidade de exportar dados e realizar análises.

\section{RESULTADOS E CONCLUSÕES}

Anteriormente à moldagem dos corpos de prova, foi realizado o ensaio de abatimento do tronco de cone, também conhecido por slump test. Os traços piloto, Cyrel ${ }^{\varpi}$, PET e Pellets obtiveram valores de abatimento de 80,0 $\mathrm{mm}, 75,0 \mathrm{~mm}, 70,0 \mathrm{~mm}$ e $100,0 \mathrm{~mm}$, respectivamente. Observa-se que os três primeiros traços obtiveram valores satisfatórios de abatimento, enquanto o quarto traço apresentou um valor maior do que o preconizado. Isso se deve, provavelmente, ao fato de que a superfície dos pellets é extremamente lisa, prejudicando a aderência entre os componentes do concreto.

A tabela 5 apresenta os valores de resistência à compressão dos quatro traços, bem como o desvio padrão e o coeficiente de variação para a idade de 28 dias. Ressaltase que os valores de resistência à compressão obtidos experimentalmente foram corrigidos por intermédio da curva de calibração da prensa. 
Tabela 05: Resistência à compressão (MPa), desvio padrão (MPa) e Cv (\%)

\begin{tabular}{c|c|c|c|c}
\cline { 2 - 5 } & Piloto & Cyrel® & PET & Pellets \\
\hline $\begin{array}{c}\text { Resistência } \\
\text { média (MPa) }\end{array}$ & 23,877 & 18,527 & 20,055 & 21,152 \\
\hline $\begin{array}{c}\text { Desvio padrão } \\
\text { (MPa) }\end{array}$ & 0,758 & 0,857 & 0,914 & 0,852 \\
\hline Cv (\%) & 3,20 & 4,70 & 4,60 & 4,00 \\
\hline
\end{tabular}

Fonte: Elaborado pelos autores

Com base nos dados apresentados, pode-se observar que o traço piloto atingiu o maior valor de resistência média, bem como o menor desvio padrão entre as resistências dos 13 corpos de prova, e consequentemente, o menor coeficiente de variação.

Com relação aos traços com substituição parcial de agregado miúdo por resíduos plásticos, ressalta-se que em comparação ao traço piloto, houve perda na resistência a compressão de todos os traços. Contudo, o traço com substituição de $\mathrm{Cyrel}^{\oplus}$ apresentou maiores perdas de resistência, seguido do traço com substituição de PET. Por fim, o traço com valores de resistência que mais se aproximaram do traço piloto foi o traço 04 , com substituição de Pellets.

Para analisar os valores de desvio padrão e Coeficiente de variação dos traços, utilizou-se como parâmetro a norma de controle de concreto americana - ACI214 (ACl, 2002). Com base nas tabelas localizadas na página $06 \mathrm{da}$ norma, pode-se classificar o desvio padrão de todos os traços como 'excelente', enquanto o coeficiente de variação dos traços 01, 02, 03 e 04 foi classificado como 'bom', 'razoável', 'razoável' e 'bom', respectivamente.

Cita-se que para o cálculo dos valores apresentados na tabela 6 foram retirados os resultados de resistência dos corpos de prova cujos valores foram discrepantes.

Com relação ao módulo de elasticidade não destrutivo, foram moldados três corpos de prova de cada traço para a realização do ensaio, conforme apresentado pela tabela 5. Para cada corpo de prova foram realizadas três determinações, e o valor apresentado na tabela 7 representa a média aritmética desses valores.

Tabela 07: Módulo de elasticidade médio (GPa) e desvio padrão médio (GPa)

\begin{tabular}{|l|l|l|}
\hline Traço & $\begin{array}{l}\text { Módulo de elastici- } \\
\text { dade médio }(\mathbf{G P a})\end{array}$ & $\begin{array}{l}\text { Desvio padrão } \\
\text { médio }(\mathbf{G P a})\end{array}$ \\
\hline Piloto & 33,27 & 0,87 \\
\hline PET & 28,32 & 0,72 \\
\hline Cyrel $^{\circledast}$ & 28,40 & 0,86 \\
\hline Pellets & 29,98 & 0,44 \\
\hline
\end{tabular}

Fonte: Elaborado pelos autores
Por fim, apresenta-se visualmente no gráfico 1 os resultados dos ensaios de Resistência à compressão simples e Módulo de elasticidade, ambas aos 28 dias, dos corpos de prova de concreto.

Gráfico 01: RCS médio (Mpa) e Módulo de elasticidade médio (GPa)

\section{RCS e Módulo de Elasticidade aos 28 Dias}

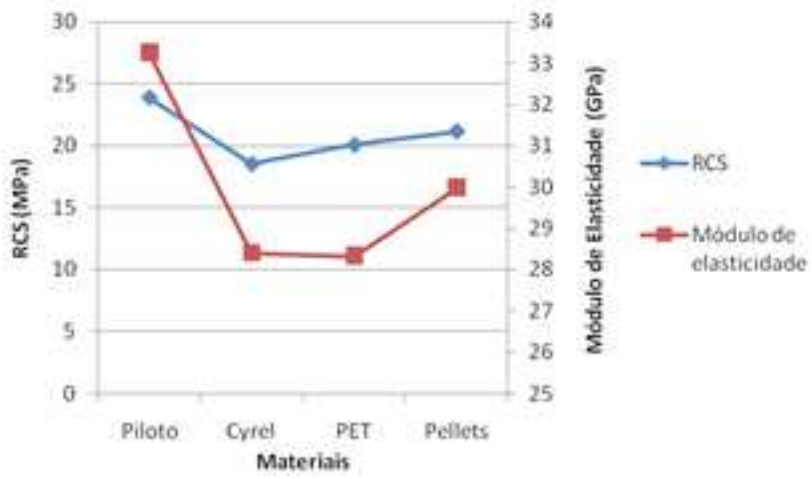

Fonte: Elaborado pelos autores

Analisando os valores obtidos, percebe-se que há semelhança entre os valores do módulo de elasticidade e os valores de resistência à compressão simples. Observando cada traço, é possível inferir que o traço piloto atingiu valores maiores de módulo de elasticidade, e nos outros traços houve reduções - por mais que pequenas -, se comparando com o traço piloto.

Em uma análise comparativa, o resíduo de Pellets de sacolas plásticas se mostrou o mais eficiente, apresentando os valores mais próximos em comparação ao traço piloto. Contudo, aponta-se que devido à perda parcial de resistência à compressão e à escassez de informações a respeito dos resíduos e sua utilização na composição do concreto, tanto os Pellets quanto o PET e o Cyrel ${ }^{\circledR}$ não poderão ser utilizados para dosagens de concreto com fins estruturais.

Contudo, recapitulando o objetivo deste trabalho de verificar possibilidades de reutilização e destino adequado aos resíduos plásticos em um contexto ambiental, constata-se a viabilidade de utilização do traço em questão.

Deste modo, ante o exposto e discutido acima, conclui-se que a substituição parcial do agregado miúdo pelos resíduos plásticos estudados neste trabalho é viável, apresentando uma solução possível, de fácil execução, e com forte aspecto ambiental. Contudo, observa-se que o concreto produzido com resíduos apresenta redução nos parâmetros estudados de resistência à compressão e módulo de elasticidade. 


\section{REFERÊNCIAS}

ABIPET (São Paulo). Indústria do PET no Brasil. 2013. Disponível em: <http://www.abipet.org.br/uploads/File/ Market Overview 2013.pdf>. Acesso em: 04 mar. 2018.

AMERICAN CONCRETE INSTITUTE. ACI 214: Evaluation of Strength Test Results of Concrete. 2 ed. Farmington Hills: 2002. 20 p.

Associação Brasileira de Empresas de Limpeza Pública e Resíduos Especiais - ABRELPE. Panorama de Resíduos Sólidos no Brasil - 2014. São Paulo: ABRELPE, 2014.

ASSOCIAÇÃO BRASILEIRA DE NORMAS TÉCNICAS. NBR 5738: Moldagem e cura de corpos-de-prova cilíndricos ou prismáticos de concreto. Rio de Janeiro: ABNT, 1994. 9 p.

ASSOCIAÇÃO BRASILEIRA DE NORMAS TÉCNICAS. NBR 6118: Projeto de estruturas de concreto - procedimento. Rio de Janeiro: ABNT, 2014. 225 p.

ASSOCIAÇÃO BRASILEIRA DE NORMAS TÉCNICAS. NBR 7217: Agregados - Determinação da composição granulométrica. Rio de Janeiro: ABNT, 1987. 3 p.

ASSOCIAÇÃO BRASILEIRA DE NORMAS TÉCNICAS. NBR 12655: Concreto de cimento Portland - Preparo, controle, recebimento e aceitação - Procedimento Rio de Janeiro: ABNT, 2015. 23 p.

ASSOCIAÇÃO BRASILEIRA DE TECNOLOGIA GRÁFICA. Manual de Impressão Flexográfica. São Paulo: ABNT. 84 p.

ASSOCIAÇÃO MERCOSSUL DE NORMALIZAÇÃO. NM 23: Cimento portland e outros materiais em pó Determinação da massa específica. Rio de Janeiro: 2000. 5 p. Acesso em: 08 set. 2017.

DEPARTAMENTO NACIONAL DE ESTRADAS DE RODAGEM. ME 081: Agregados - determinação da absorção e da densidade de agregado graúdo. Rio de Janeiro: $1998.6 \mathrm{p}$.

DEPARTAMENTO NACIONAL DE ESTRADAS DE RODAGEM. ME 084: Agregado miúdo - determinação da densidade real. Rio de Janeiro: 1995.3 p.

DUPONT. Fluxo de Trabalho Térmico $\mathrm{Cyrel}^{\circledR}$ Fast: produtividade, qualidade e sustentabilidade. Disponível em: <http://www.dupont.com.br/produtos-e-servicos/ printing-package-printing/flexographic-platemaking-systems/brands/Cyrel $\%$ products/Cyrel ${ }^{\oplus}$-FAST-thermalworkflow.html>. Acesso em: 02 set. 2017.

FADUL, Anne. PIB do setor de construção civil caiu $2,7 \%$ no $1^{\circ}$ trimestre do ano, mostra estudo da FIESP: Para a entidade o cenário é preocupante e deve piorar no segundo semestre. 2015. Disponível em: <http://www.fiesp. com.br/noticias/pib-do-setor-de-construcao-civil-caiu-27-no-1o-trimestre-do-ano-mostra-estudo-da-fiesp/>. Acesso em: 23 jun. 2017.

FORMIGONI, Alexandre; CAMPOS, Ivan Pérsio de Arruda. Reciclagem de PET no Brasil. 2006. 14 f. Tese (Doutorado) - Curso de Engenharia de Produção, Universidade Estadual Paulista, São Paulo, 2006. Disponível em: <https://www.aedb.br/seget/arquivos/ artigos07/1200_1200_ARTIGO - RECICLAGEM DE PET NO BRASIL.pdf>. Acesso em: 09 set. 2017.

GONÇALVES, Anderson Matheus Bernardino. Concretos produzidos com cinza leve do bagaço da cana-de-açúcar e resíduos de construção civil. 2017. 71 f. Dissertação (Mestrado) - Curso de Engenharia Civil, Centro de Tecnologia, Universidade Estadual de Maringá, Maringá, 2017.

GUIMARÃES, Leonardo Durval Duarte; ALBUQUERQUE, ElaineCristina Barbosa da Silva de; SANCHEZ, Sandra Barros. EMBALAGENS PLÁSTICAS COMO TEMA TRANSVERSAL NO COLÉGIO TÉCNICO DA UNIVERSIDADE RURAL DO RIO DE JANEIRO. In: COLÓQUIO INTERNACIONAL EDUCAÇÃO E CONTEMPORANEIDADE, 4., 2010, Laranjeiras. Rio de Janeiro, 2010. $14 \mathrm{p}$.

LEITE, Paulo Roberto. Logística Reversa - Meio Ambiente e Competitividade. São Paulo: Prentice Hall, 2003. 246p.

MEHTA, P.K.; MONTEIRO, Paulo J.M. Concreto microestrutura, propriedades e materiais. São Paulo. São Paulo. IBRACON, 2008.

MINISTÉRIO DO MEIO AMBIENTE (Brasil). Saco é um saco: Pra cidade, pro planeta, pro futuro e pra você. Brasília: Ministério do Meio Ambiente, 2011. 37 p. (Saco é um Saco). Disponível em: <http://www.mma.gov.br/estruturas/234/_arquivos/cartilha_3___consumidores_234. pdf >. Acesso em: 09 set. 2017. 
PEREIRA, Rita de Cássia Campos; MACHADO, Andréa Horta; SILVA, Glaura Goulart. (Re) Conhecendo o PET. Química e Sociedade, Belo Horizonte, v. 5, n. 15, p.3-5, 26 nov. 2001. Disponível em: <http://qnesc.sbq.org.br/online/qnesc15/v15a01.pdf>. Acesso em: 07 set. 2017.

PIATTI, Tania Maria; RODRIGUES, Reinaldo Augusto Ferreira. Plásticos: características, usos, produção e impactos ambientais. Alagoas: Editora da Universidade Federal de Alagoas, 2005. 51 p. (Conversando sobre Ciências em Alagoas). Disponível em: <http://www.usinaciencia. ufal.br/multimidia/livros-digitais-cadernos-tematicos/ Plasticos_caracteristicas_usos_producao_e_impactos_ ambientais.pdf >. Acesso em: 03 set. 2017.

ROMÃO, Wanderson; SPINACÉ, Márcio A. S.; PAOLI, Marco A. de. Poli(Tereftalato de Etileno), PET: Uma Revisão Sobre os Processos de Síntese, Mecanismos de Degradação e sua Reciclagem. Polímeros: Ciência e Tecnologia, Campinas, v. 19, n. 2, p.121-132, jan. 2009. Disponível em: <http://www.scielo.br/pdf/po/v19n2/ v19n2a09>. Acesso em: 02 set. 2017.

SANTOS, Samantha Fonseca dos. Análise de filmes poliméricos densos de AcC/PHAmcl por técnicas de DSC, DMA, XPS, Ângulo de Contato e AFM. 2005. 70 f. Dissertação (Mestrado) - Curso de Física, Pontifícia Universidade Católica do Rio de Janeiro, Rio de Janeiro, 2005. Disponível em: <http://www2.dbd.puc-rio.br/ pergamum/tesesabertas/0312428_05_pretextual.pdf $>$. Acesso em: 02 set. 2017.

ZIEGLER, Maria Fernanda. Por que a sacola de plástico é prejudicial ao meio ambiente: Entenda o problema das sacolas plásticas e quais as alternativas ambientalmente corretas para transportar suas compras. IG: São Paulo, 2010. Disponível em:< http://ultimosegundo.ig.com.br/ ciencia/meioambiente/por-que-a-sacola-de-plastico-e-prejudicial-ao-meio-ambiente/n1237730908104.html>. Acesso em: 09 jan 2013. 